\title{
Transition of pediatric liver transplant recipients to adult care: Patient and parent perspectives
}

Fredericks EM, Dore-Stites D, Lopez MJ, Well A, Shieck V, Freed GL, Eder SJ, Magee JC. Transition of pediatric liver transplant recipients to adult care: Patient and parent perspectives.

Pediatr Transplantation 2011: 15: 414-424. (C) 2011 John Wiley \& Sons A/S.

Abstract: The need to prepare pediatric transplant recipients for the transfer to adult-centered transplant care has received increased attention. This study aimed to determine adolescent and young adult LTR and parent perceptions and attitudes about the transition process. LTR and their parents completed a survey assessing level of prior thought and interest in learning about transferring care, knowledge of the transition process, perceived importance of self-management skills, concerns about moving to the adult clinic, and responsibility for health management tasks. Responses were analyzed by age, gender, and time since transplantation. Participants included 46 LTR (mean age $=16.6 \mathrm{yr}$; range $12-21$ ), and 31 parents. Recipients and parents reported moderate concern about transition, with leaving pediatric providers being a primary worry. LTR $\geq 16 \mathrm{yr}$ reported greater health care responsibility and increased thought, interest, and knowledge about transition. There were significant differences between parent and LTR perceptions of health care responsibility, indicating that LTR perceive having more independence than what their parents report. Overall, results suggest that adolescent and young adult LTR and their parents perceive the importance of transitional care, but demonstrate poor knowledge of the process. There remains a need for improved transition planning for both adolescents and parents.

\section{Emily M. Fredericks', Dawn Dore-Stites ${ }^{1}$, M. James Lopez ${ }^{1}$, Andrew Well', Victoria Shieck', Gary L. Freed ${ }^{1}$, Sally J. Eder ${ }^{1}$ and John C. Magee ${ }^{2}$}

Departments of ${ }^{1}$ Pediatrics and ${ }^{2}$ Surgery, University of Michigan Health System, Ann Arbor, MI, USA
Key words: transition - adolescents - young adults pediatric liver transplantation - adult care

Emily M. Fredericks, PhD, Department of Pediatrics, University of Michigan Health System, 1924 Taubman Center, SPC 5318, 1500 E. Medical Center Drive, Ann Arbor, MI 48109-5318, USA

Tel.: (734) 6153866

Fax: (734) 9366897

E-mail: emfred@med.umich.edu

Accepted for publication 18 February 2011
With an increasing number of pediatric transplant recipients reaching young adulthood $(1,2)$, emphasis has been placed on the need to transfer from pediatric to adult-centered health care. "Transition" is defined as an active process that addresses the medical, psychosocial, and educational/vocational needs of adolescents as they prepare to move from child- to adult-centered health care (3), while "transfer" is the physical change in the location where care is provided $(4,5)$.

It is recommended that prior to transferring to adult-centered care, the pediatric transplant

\footnotetext{
Abbreviations: CCTC, certified clinical transplant coordinators; CCTN, certified clinical transplant nurses; ER, emergency room; LTR, liver transplant recipient.
}

recipient should be able to describe the reason for their transplant; be aware of how transplantation impacts on their overall health; demonstrate a sense of responsibility and have the capacity to independently manage their health (6). Moreover, it has been recommended that prior to physically transferring to the adultcentered clinic, pediatric transplant recipients should be able to describe their medication regimen, refill prescriptions independently, recognize how and when to seek medical attention, and be able to communicate with their healthcare providers (6).

In adult care settings, patients are expected to demonstrate self-management skills including the ability to independently discuss medical care with the treatment team, schedule and attend appointments, and adhere to medications and treatment 
recommendations (7). Unfortunately, young adults who underwent liver transplantation in childhood are at risk for delayed autonomy and medication non-adherence (8). This has significant implications for pediatric providers as it is recommended that adolescents acquire self-management skills prior to the transfer to adultcentered health care (6). Yet, to date, there is limited research investigating the transition process among adolescent solid organ transplant recipients (9-14).

Our pediatric liver transplant program has been focused on the assessment of transition readiness skills to develop interventions to improve outcomes following the transfer to adult care (11). As part of our ongoing efforts, we conducted a cross-sectional study to investigate adolescent and young adult LTRs' and their parents' perspectives on the transition process. We assessed the level of prior thought about transferring to an adult transplant program, interest in and knowledge of the transition process, perceived importance of self-management skills, concerns about the transfer, and allocation of responsibility for health management tasks.

\section{Methods}

\section{Study population}

Adolescent and young adult LTRs (ages 12-21) who were $>6$ months post-transplantation and their parents, when present, were approached prior to their Pediatric Liver Transplant clinic visit and recruited to complete an anonymous survey of transition perspectives. This assessment is part of our program's ongoing efforts to develop a program to improve the process of transitioning from pediatric to adult-centered care (11). Participants in the current study were an independently recruited sample from the Pediatric Liver Transplant clinic and were not enrolled in a formal transitional care program at the time of survey completion. Fifty eligible recipients presented in the clinic between August 2009 and May 2010. Thirty-one recipients between the ages of 12-17 participated along with their parent/guardian, and 15 recipients $\geq 18 \mathrm{yr}$ of age participated without a parent/guardian for a total of 46 recipients and 31 parents. This represents a recruitment rate of $92 \%$. Patients self-reported their gender, current age, and age at transplantation. The medical center's Institutional Review Board approved all aspects of this study.

\section{Assessment of transition perceptions and attitudes}

Our previous work in transition readiness (11) did not specifically assess the attitudes and perceptions of the transition process. To explore these areas, we adapted a questionnaire used in a sickle cell population (15) to assess perspectives related to transition across the following domains: (i) level of prior thought; (ii) level of interest in transition; (iii) knowledge of the transition process; (iv) perceived importance of tasks related to transitioning to adult care; and (v) concerns about the transfer. Published literature and anecdotal evidence indicate the importance of assessing the allocation of responsibility for health-related tasks $(11,16)$, thus we included items from other psychometrically sound measures of allocation of responsibility in children with asthma $(11,17)$, and pediatric LTRs (11) in this current survey (Table 1).

Level of prior thought and interest were graded on a 3-point scale ranging from "not at all" to "a lot." Items assessing knowledge of the process, perceived importance, and concerns about the transfer were rated on a 4-point scale. Knowledge of the transition process was scaled $0-4$ reflecting the number of steps known to the participant. Allocation of responsibility for healthcare tasks was scaled 1-5 (parents alone $=1$, adolescent/young adults alone $=5$ ). Recipients and parents ranked their preferred method for receiving information about the transition process and the transfer to adult-centered care. Finally, respondents answered two open-ended questions regarding potential concerns and strategies for improving the transition process.

Table 1. Survey items assessing patient and parent perspectives on transitioning from pediatric to adult liver transplant clinic

1. Prior thought: how much have you thought about moving from the pediatric liver transplant clinic to an adult liver transplant clinic? $(0=$ not at all, $3=$ a lot $)$

2. Interest in learning about transition: how interested are you in learning about the transition process now? $(0=$ not at all, $3=$ very interested $)$

3. Knowledge of the transition process: what do you know about the transition process (please circle all that apply)

a. I know which hospital or doctor I will transfer to

b. I know what information needs to be sent to my new doctor

c. I know how to make an appointment with my new doctor

d. I know if my insurance will be accepted at the new hospital

4. Concerns about the transfer of care: when thinking about transferring to an adult clinic, what are you most concerned about? $(0=$ not concerned;

$4=$ very concerned)

a. Leaving behind my previous physician

b. Having to meet new caregivers

c. Not receiving as good medical care

d. Adult caregivers not being as caring

e. Being admitted to the adult hospital or adult floor

f. Being able to take care of my health by myself

5. Importance of steps in the transition process: what do you think is important to know and do so that you can manage or take care of your health on your own? ( $0=$ not important, $4=$ very Important)

a. Knowing about your medicines

b. Knowing what your labs mean

c. Knowing about sex/having children

d. Knowing about insurance coverage

e. Knowing when to go to the ER

6 . Allocation of responsibility: who is usually responsible for the following? ( $1=$ parent/caregiver alone; $5=$ adolescent/young adult alone)

a. Calling for your prescription refills

b. Remembering to take medications

c. Remembering to get labs drawn

d. Scheduling medical appointments

e. Calling the doctor/nurse with questions

7. What can we do to help prepare you and your family for the transition from the Pediatric Liver Transplant Clinic to the Adult Liver Transplant Clinic?

8. What questions or concerns do you have about transitioning from your pediatric team to the adult team? 


\section{Fredericks et al.}

\section{Data analysis}

Mean scores for the six domains were determined and reported as mean \pm standard deviation. With the exception of the domain measuring parents' perceived importance of transition readiness, data were normally distributed and Pearson's product moment correlation coefficients were calculated to determine associations between measured domains and age, gender and time since transplantation. Spearman's rank correlation coefficients were calculated to examine the associations between parents' perceived importance of transition readiness and adolescent demographic factors. The level of agreement between parent and patient reports were analyzed using paired correlations. Discrepancies between parent and patient reports were examined using paired sample $t$-tests. We further examined the level of agreement between patient and parent perceptions of allocation of responsibility for health-management tasks by examining patterns of agreement between respondents. Two patterns, "over allocation" and "under allocation" were identified. "Over allocation" of responsibility refers to a pattern in which the adolescent endorses that they are responsible for a given task, and the parent reports that the adolescent is not. "Under allocation" refers to a pattern in which the adolescent endorses minimal responsibility, but the parent reports that the adolescent is primarily responsible. All analyses were conducted using PASW Statistics 18 for Windows (Version 18.0; SPSS, Inc., 2009, Chicago, IL, USA).

\section{Results}

Participant characteristics

Participants included 46 pediatric LTRs. Mean adolescent age was $16.4 \pm 2.5 \mathrm{yr}$ (range 12 $21 \mathrm{yr}$ ) with an average time since transplant of $10.0 \pm 4.9 \mathrm{yr}$ (range $3-19 \mathrm{yr}$ ). Mean age at the time of transplantation was $6.18 \pm 4.9 \mathrm{yr}$ (range 1-16 yr). Parent reports were available for 31 patients. Mean age for recipients with corresponding parent reports was $15.06 \pm 1.6$ (range 12-17 yr), compared to the mean age of $19.43 \pm 1.03$ (range $18-21 \mathrm{yr}$ ) for recipients without parent report $(\mathrm{N}=15)$. The majority of participants were women $(54 \%)$.

\section{Prior thought about the transition process}

Prior thought about transition ranked low among patients (mean score of $0.87 \pm 0.94$; maximum three points possible). Nineteen patients $(42 \%)$ reported no prior thought about transition. Parents also reported little prior thought with mean scores of $0.94 \pm 1.03$. Fifteen parents $(48 \%)$ reported that they had not thought about transition at all.

Interest in the transition process

Adolescent/young adult recipients reported moderate levels of interest in learning about the transition process $(1.6 \pm 0.96$; maximum three points possible), with $54 \%$ of recipients reporting "some" or "a lot" of interest (scores 2-3). Parents reported similar levels of interest in learning about transition, with mean scores of $1.8 \pm 1.06$. Nineteen parents $(61 \%)$ reported "some" or "a lot" of interest (scores 2-3) in learning about the process.

\section{Knowledge about the transition process}

Adolescent/young adult recipient knowledge of the basic steps in the transition process ranked lowest among the six components of the survey (mean $=1.09 \pm 0.14 ;$ maximum four points possible). Approximately one-third of recipients $(32.6 \%)$ reported they knew what information needed to be transferred to their new provider. Ten $(21.7 \%)$ reported knowing which hospital/ doctor they would be transferring care to, 13 $(28.3 \%)$ reported they knew how to make an appointment with their new clinic/doctor, and 12 $(26.1 \%)$ reported knowing whether their insurance would be accepted by their new provider/ clinic.

Parent knowledge of the basic steps in the transition process also ranked lowest across the domains assessed (mean score of $1.1 \pm 1.4$; maximum four points possible). Approximately one-third of parents reported having knowledge about what information needed to be sent to the new provider (nine parents, 29\% each). Likewise, nine parents $(29 \%)$ reported knowing if their adolescent's insurance would be accepted at the new hospital/clinic. Eight parents (17\%) reported knowing which clinic/provider their adolescent would transfer to, and eight parents $(17 \%)$ reported knowing how to make an appointment with the adult clinic.

\section{Areas of concern}

Adolescent/young adult recipients reported moderate levels of concern about the transfer, with a mean score of $2.0 \pm 1.1(0=$ not concerned, $4=$ very concerned). The most common area of concern for recipients was that the adult team will not be as caring $(2.33 \pm 1.46)$. Recipients also identified leaving pediatric providers behind $(2.28 \pm 1.39)$, potential decline in quality of medical care $(2.14 \pm 1.56)$, having to meet new caregivers $(1.96 \pm 1.3)$, being admitted to the adult hospital facilities $(1.9 \pm 1.52)$, and being able to independently manage health care needs $(1.91 \pm 1.58)$ as additional areas of concern.

Parents also reported moderate levels of concern about the transfer $(2.5 \pm 1.6)$, with leaving pediatric providers behind being the greatest worry $(3.19 \pm 1.4)$. Parents also reported 
concern about their adolescents' ability to independently manage health care needs $(3.03 \pm$ 1.22); having their adolescent admitted to the adult hospital facilities $(2.43 \pm 1.52)$; having to meet new providers $(2.42 \pm 1.70)$; adult providers not being as caring $(2.26 \pm 1.61)$; and potential decline in quality of medical care for their adolescent $(2.03 \pm 1.64)$ as additional areas of concern.

\section{Perceived importance of self-management tasks}

Adolescent/young adult recipients perceive selfmanagement tasks as an important component to the transition process with mean scores of $3.4 \pm 0.74$ of a possible four points $(0=$ not important, $4=$ very important). Recipients reported that knowledge about medications $(3.8 \pm 0.5)$ is the most important step in transition. They also placed high importance on knowledge about reproductive health $(3.16 \pm 1.30)$, meaning of lab values $(3.53 \pm 0.79)$, insurance coverage $(3.07 \pm 1.39)$, and knowing when to go to the ER for medical attention $(3.49 \pm 0.9)$.

Parents also perceive self-management tasks as important in the transition process with mean scores of $3.5 \pm 0.79$. Parents reported that knowledge about when to go to the ER $(3.70 \pm 0.84)$ is the most important skill. They also placed high importance on knowledge about medications $(3.65 \pm 0.75)$, the meaning of labs $(3.61 \pm 0.76)$, reproductive health $(3.29 \pm 1.24)$ and insurance coverage $(3.26 \pm 1.15)$.

\section{Allocation of responsibility for health care tasks}

Adolescent/young adult recipient scores on the allocation of responsibility scale $(\mathrm{M}=2.8 \pm$ 1.2) indicate that recipients perceive that responsibility for health-related tasks is shared equally with their parent/guardian (Table 2). Across items for all participants, responsibility for medication taking was most commonly allocated to the patient. Among parents, the allocation of responsibility scale $(\mathrm{M}=1.69 \pm 0.61)$ suggests that overall parents perceive that most healthcare tasks are the responsibility of the parent/ caregiver alone. Similar to the patient selfreports, responsibility for medication taking was most commonly allocated to the adolescent/young adult alone $(\mathrm{M}=3.07 \pm 1.1)$.

For the 31 patient-parent dyads, paired sample t-tests revealed significant differences between parent and adolescent reports on this domain $(t=4.89 ; \mathrm{p}=0.0001)$ indicating that adolescents perceive more shared responsibility for health-related tasks $(M=2.36 \pm 0.97)$ than what their parents report $(\mathrm{M}=1.68 \pm 0.61)$. An analysis of response patterns across items revealed that with respect to responsibility for obtaining prescription refills and making appointments, patients and parents were in agreement that the parent shouldered most of the responsibility. Adolescents perceived they had more responsibility than their parents reported with respect to medication administration $(37.9 \%)$, remembering lab draws $(48 \%)$, and calling the healthcare team with questions (39\%).

There were no other significant differences between patient and parent reports on the survey.

\section{Transition perceptions and recipient demographics}

The association between transition perceptions and patient age, time since transplantation and gender were examined (Table 3). Recipient age was significantly correlated with knowledge about transition $(r=0.37, \mathrm{p}=0.013)$, prior

Table 2. Allocation of responsibility for health-management tasks

\begin{tabular}{|c|c|c|c|c|}
\hline $\begin{array}{l}\text { Who is usually responsible for the } \\
\text { following tasks? (parent alone }=1 \text {, } \\
\text { A/YA alone }=5 \text { ) }\end{array}$ & $\begin{array}{l}\text { A/YA report } \\
(\mathrm{M} \pm \text { s.d.) }\end{array}$ & $\begin{array}{l}\text { Parent report } \\
(\mathrm{M} \pm \text { s.d.) }\end{array}$ & Significance* & $\begin{array}{l}\text { Response } \\
\text { pattern }\end{array}$ \\
\hline Calling for your prescription refills & $2.00 \pm 1.4$ & $1.65 \pm 1.22$ & $\begin{array}{l}t=1.9 \\
p=0.062\end{array}$ & $\begin{array}{l}\text { 19.4\% A/YA over allocation } \\
74.2 \% \text { agree }\end{array}$ \\
\hline Remembering to take medications & $3.72 \pm 1.28$ & $3.07 \pm 1.16$ & $\begin{array}{l}t=3.78 \\
p=0.001^{*}\end{array}$ & $\begin{array}{l}37.9 \% \text { A/YA over allocation } \\
58.6 \% \text { agree }\end{array}$ \\
\hline Remembering to get labs drawn & $2.38 \pm 1.08$ & $1.34 \pm 0.67$ & $\begin{array}{l}t=5.9 \\
p=0.0001^{*}\end{array}$ & $\begin{array}{l}\text { 48.3\% A/YA over allocation } \\
51.7 \% \text { agree }\end{array}$ \\
\hline Scheduling medical appointments & $1.66 \pm 1.11$ & $1.21 \pm 0.56$ & $\begin{array}{l}t=2.65 \\
p=0.013^{*}\end{array}$ & $\begin{array}{l}13.8 \% \text { A/YA Over allocation } \\
86.2 \% \text { agree }\end{array}$ \\
\hline Calling the doctor/nurse with questions & $2.21 \pm 1.40$ & $1.29 \pm 0.85$ & $\begin{array}{l}t=3.69 \\
p=0.001\end{array}$ & $\begin{array}{l}39.3 \% \text { A/YA Over allocation } \\
60.7 \% \text { agree }\end{array}$ \\
\hline
\end{tabular}




\section{Fredericks et al.}

Table 3. Transition perceptions of older adolescents/young adults compared to younger adolescents

\begin{tabular}{|c|c|c|c|c|c|}
\hline & & $\mathrm{N}$ & Mean & s.d. & p-value \\
\hline \multirow[t]{2}{*}{ Prior thought about transition ( $0=$ no thought, $3=$ a lot of thought $)$} & $12-15$ yr & 16 & 0.37 & 0.62 & \multirow[t]{2}{*}{$0.008^{*}$} \\
\hline & $16-21 \mathrm{yr}$ & 29 & 1.14 & 0.99 & \\
\hline \multirow[t]{2}{*}{ Interest in learning about transition/transfer $(0=$ no interest, $3=$ very interested $)$} & $12-15 \mathrm{yr}$ & 16 & 1.12 & 0.96 & \multirow[t]{2}{*}{$0.021^{*}$} \\
\hline & $16-21 \mathrm{yr}$ & 30 & 1.80 & 0.89 & \\
\hline \multirow[t]{2}{*}{ Knowledge of transition steps $(0=$ no, yes $=1)$} & $12-15 \mathrm{yr}$ & 16 & 0.56 & 0.73 & \multirow[t]{2}{*}{$0.007^{*}$} \\
\hline & $16-21 \mathrm{yr}$ & 30 & 1.37 & 0.99 & \\
\hline \multirow[t]{2}{*}{ I know which hospital or doctor I will transfer to } & $12-15 \mathrm{yr}$ & 16 & 0.13 & 0.34 & \multirow[t]{2}{*}{0.277} \\
\hline & $16-21 \mathrm{yr}$ & 30 & 0.27 & 0.45 & \\
\hline \multirow[t]{2}{*}{ I know what information needs to be sent to my new doctor } & $12-15$ yr & 16 & 0.19 & 0.40 & \multirow[t]{2}{*}{0.150} \\
\hline & $16-21 \mathrm{yr}$ & 30 & 0.4 & 0.50 & \\
\hline \multirow[t]{2}{*}{ I know how to make an appointment with my new doctor } & $12-15 \mathrm{yr}$ & 16 & 0.06 & 0.25 & \multirow[t]{2}{*}{0.015} \\
\hline & $16-21 \mathrm{yr}$ & 30 & 0.40 & 0.50 & \\
\hline \multirow[t]{2}{*}{ I know if my insurance will be accepted at the new hospital } & $12-15 \mathrm{yr}$ & 16 & 0.19 & 0.40 & \multirow[t]{2}{*}{0.419} \\
\hline & $16-21 \mathrm{yr}$ & 30 & 0.30 & 0.47 & \\
\hline \multirow[t]{2}{*}{ Concerns about transferring care ( $0=$ no concerns, $4=$ a lot of concern) } & $12-15$ yr & 16 & 2.16 & 1.14 & \multirow[t]{2}{*}{0.621} \\
\hline & $16-21 \mathrm{yr}$ & 30 & 1.99 & 1.12 & \\
\hline \multirow[t]{2}{*}{ Leaving behind previous physician when transferring to adult clinic } & $12-15 \mathrm{yr}$ & 16 & 2.38 & 1.36 & \multirow[t]{2}{*}{0.747} \\
\hline & $16-21 \mathrm{yr}$ & 30 & 2.23 & 1.43 & \\
\hline \multirow[t]{2}{*}{ Having to meet new caregivers when transferring to adult clinic } & $12-15 \mathrm{yr}$ & 16 & 1.81 & 1.52 & \multirow[t]{2}{*}{0.603} \\
\hline & $16-21 \mathrm{yr}$ & 29 & 2.03 & 1.27 & \\
\hline Not receiving as good of medical care after transfer to adult clinic & $12-15 \mathrm{yr}$ & 15 & 2.40 & 1.77 & 0.428 \\
\hline & $16-21 \mathrm{yr}$ & 29 & 2.00 & 1.46 & \\
\hline Adult caregivers not being as caring & $12-15$ yr & 16 & 2.38 & 1.54 & 0.889 \\
\hline & $16-21 \mathrm{yr}$ & 29 & 2.31 & 1.44 & \\
\hline Being admitted to the adult hospital or adult floor after transfer to adult clinic & $12-15 \mathrm{yr}$ & 16 & 1.88 & 1.67 & 0.912 \\
\hline & $16-21 \mathrm{yr}$ & 28 & 1.93 & 1.46 & \\
\hline Being able to take care of my health by myself after transfer to adult clinic & $12-15 \mathrm{yr}$ & 16 & 2.19 & 1.56 & 0.389 \\
\hline & $16-21 \mathrm{yr}$ & 29 & 1.76 & 1.60 & \\
\hline Perceived importance of transition skills/tasks ( $0=$ not important; $4=$ very important) & $12-15 \mathrm{yr}$ & 16 & 3.26 & 0.82 & 0.332 \\
\hline & $16-21 \mathrm{yr}$ & 29 & 3.49 & 0.70 & \\
\hline Knowing about your medicines & $12-15 \mathrm{yr}$ & 16 & 3.69 & 0.60 & 0.224 \\
\hline & $16-21 \mathrm{yr}$ & 29 & 3.86 & 0.35 & \\
\hline Knowing what your labs mean & $12-15 \mathrm{yr}$ & 16 & 3.25 & 1.00 & 0.072 \\
\hline & $16-21 \mathrm{yr}$ & 29 & 3.69 & 0.60 & \\
\hline Knowing about sex/having children & $12-15 \mathrm{yr}$ & 16 & 3.06 & 1.44 & 0.725 \\
\hline & $16-21 \mathrm{yr}$ & 29 & 3.21 & 1.24 & \\
\hline Knowing about insurance coverage & $12-15$ yr & 16 & 2.69 & 1.49 & 0.176 \\
\hline & $16-21 \mathrm{yr}$ & 29 & 3.28 & 1.31 & \\
\hline Knowing when to go to the ER & $12-15 \mathrm{yr}$ & 16 & 3.63 & 0.72 & 0.455 \\
\hline & $16-21 \mathrm{yr}$ & 29 & 3.41 & 0.98 & \\
\hline Allocation of responsibility ( $1=$ parent alone; $5=$ adolescent alone $)$ & $12-15 \mathrm{yr}$ & 16 & 2.01 & 1.01 & $0.001^{*}$ \\
\hline & $16-21 \mathrm{yr}$ & 30 & 3.21 & 1.09 & \\
\hline Who is usually responsible for calling for your prescription refills? & $12-15$ yr & 16 & 1.75 & 1.18 & $0.007^{*}$ \\
\hline & $16-21 \mathrm{yr}$ & 30 & 3.10 & 1.71 & \\
\hline Who is usually responsible for remembering to take medications? & $12-15$ yr & 15 & 3.33 & 1.11 & $0.021^{*}$ \\
\hline & $16-21 \mathrm{yr}$ & 30 & 4.23 & 1.22 & \\
\hline Who is usually responsible for scheduling medical appointments? & $12-15 \mathrm{yr}$ & 15 & 1.53 & 1.13 & $0.035^{*}$ \\
\hline & $16-21 \mathrm{yr}$ & 28 & 2.54 & 1.58 & \\
\hline Who is usually responsible for calling the doctor/nurse with questions? & $12-15 \mathrm{yr}$ & 15 & 1.67 & 1.29 & $0.002^{*}$ \\
\hline & $16-21 \mathrm{yr}$ & 28 & 3.11 & 1.44 & \\
\hline Who is usually responsible for remembering to get labs drawn? & $12-15$ yr & 15 & 2.07 & 1.16 & $0.017^{*}$ \\
\hline & $16-21 \mathrm{yr}$ & 28 & 3.07 & 1.30 & \\
\hline
\end{tabular}

${ }^{*} p<0.05$.

thought about the process $(r=0.63, \mathrm{p}=$ 0.0001 ), interest in learning about transition $(r=0.37, \mathrm{p}=0.011)$, and allocation of responsibility $(r=0.66, \mathrm{p}=0.0001)$.

Follow-up univariate analyses between older adolescents/young adults ( $\geq 16 \mathrm{yr}$ ) and younger adolescents $(\leq 15 \mathrm{yr})$ revealed that the older group had more knowledge about the steps in the transition process $(t=2.84 ; \mathrm{p}=0.007)$, gave more thought to transferring care $(t=2.79$; $\mathrm{p}=0.008)$, had greater interest in learning about the process $(t=2.39, \mathrm{p}=0.02)$, and were more independent in health-related tasks $(t=3.65 ; \mathrm{p}=0.001)$. There were no differences 
in transition perceptions among recipients based on time since transplantation. There were no significant interactions between age and time since transplantation with respect to transition perceptions and attitudes.

With respect to gender differences, female recipients placed higher importance on medication knowledge during the transition process $(\mathrm{M}=3.92 \pm 0.28)$ than males $(\mathrm{M}=3.65 \pm$ $0.58 ; t=2.03, \mathrm{p}=0.048)$. Female recipients also reported more independence in remembering to take medications as compared to males $(\mathrm{M}=$ $4.28 \pm 0.98$ vs. $\mathrm{M}=3.5 \pm 1.4 ; t=2.16, \mathrm{p}=$ $0.036)$. There were no gender differences on remaining survey items.

There were no differences in parental reports of transition perceptions based on patient age, time since transplantation, or gender.

Responses to open-ended questions related to suggestions and concerns about the transition process

Based on the two open-ended questions presented, the majority of adolescent/young adults did not offer suggestions for improving the transition process (Table 4). Those who did offer suggestions requested that general information regarding the transfer process, including the timing of transfer and insurance coverage be provided. For example, one patient said, "You could tell us when or what age I'll be, what I have to do and help me understand the changing process more." Recipients also expressed concerns related to the emotional aspects of transferring care, including meeting new providers and remaining in contact with pediatric providers. One patient indicated

Table 4. Responses to open-ended questions eliciting suggestions and concerns related to the transition process

\begin{tabular}{|c|c|c|}
\hline & $\begin{array}{l}\text { Number of } \\
\text { adolescents/ } \\
\text { young adults (\%) }\end{array}$ & $\begin{array}{l}\text { Number of } \\
\text { parents }(\%)\end{array}$ \\
\hline \multicolumn{3}{|l|}{ Suggestions for improvement } \\
\hline No additional suggestions given & $29(63)$ & $15(48)$ \\
\hline $\begin{array}{l}\text { Provision of general information } \\
\text { regarding transfer process } \\
\text { (e.g., timing, insurance coverage) }\end{array}$ & $12(26)$ & $12(39)$ \\
\hline Meeting new providers prior to transfer & $5(11)$ & $3(13)$ \\
\hline \multicolumn{3}{|l|}{ Concerns about transition process } \\
\hline No additional concerns or worries & $36(75)$ & $16(51)$ \\
\hline Meeting new providers & $4(9)$ & $7(23)$ \\
\hline Leaving pediatric providers & $2(4)$ & $7(23)$ \\
\hline Age of transfer & $2(4)$ & $4(13)$ \\
\hline Location of adult clinic & $2(4)$ & $1(3)$ \\
\hline $\begin{array}{l}\text { Transferring a teen with } \\
\text { developmental delay }\end{array}$ & - & $1(3)$ \\
\hline $\begin{array}{l}\text { "The basics" (e.g., timing, } \\
\text { location, age) }\end{array}$ & - & $1(3)$ \\
\hline
\end{tabular}

readiness for transfer, stating, "Transfer me." Similarly, among parents, nearly half did not offer any suggestions for the improvement of the transition process. More than a third of parents made suggestions regarding the provision of general information including the timing of the transfer and the location of the new provider. As one parent stated, "I just need to know where and when." The remaining parents made recommendations related to opportunities to meet the new providers prior to the transfer of care. For example, one parent said, "I am hoping we're introduced to everyone and shown around the clinic area."

With respect to concerns about the transition process, the majority of recipients denied any concerns or worries beyond those endorsed on previous survey items (Table 4). Those that did express worry focused on concerns related to meeting new providers, leaving pediatric providers, logistics related to the timing of transfer and location of the new clinic, and insurance coverage. Approximately half of the parents denied worries or concerns about the transition process that were not included on the survey. Parents who endorsed worries were most concerned about leaving pediatric providers and meeting new providers. For example, one parent asked "how close will they monitor her?" while another asked if they could "just stay with her previous caregivers as long as possible."

\section{Preferred method of receiving transition-related information}

The most preferred method for receiving transition-related information among recipients and parents was face-to-face contact with someone from the pediatric or adult team. Other mechanisms identified included the internet/website, handouts/brochures, or a group format with other transitioning recipients/families (Table 5).

Table 5. Preferred method for receiving transition-related information

\begin{tabular}{llr}
\hline & $\begin{array}{l}\text { Number of } \\
\text { adolescents/ } \\
\text { young adults* (\%) }\end{array}$ & $\begin{array}{l}\text { Number of } \\
\text { parents* }\end{array}$ \\
\hline $\begin{array}{l}\text { Face-to-face with someone } \\
\text { from the pediatric team }\end{array}$ & $13(37)$ & $19(73)$ \\
$\begin{array}{l}\text { Face-to-face with someone } \\
\text { from the adult team }\end{array}$ & $13(37)$ & $11(44)$ \\
$\begin{array}{l}\text { Internet/website } \\
\text { Handouts/brochure }\end{array}$ & $8(24)$ & $5(22.7)$ \\
$\begin{array}{l}\text { Group format with other } \\
\text { transitioning recipients/families }\end{array}$ & $6(18.2)$ & $9(34.6)$ \\
& $3(9.7)$ & $2(9.5)$ \\
\hline
\end{tabular}

*Thirty-five adolescent/young adults and 26 parents answered this survey item. 


\section{Fredericks et al.}

\section{Discussion}

Transition planning is a key developmental process among adolescent/young adults with chronic health conditions, and should begin well in advance of the anticipated transfer from pediatric to adult-centered care. To develop patient-oriented transition programs, we sought to determine patients' and their parents' attitudes, concerns and perceptions about transferring care. Given emphasis placed on increasing patient readiness and independent health self-management skills prior to transferring care $(6,11,18,19)$, we also examined perceptions about the allocation of responsibility for health management tasks.

\section{Attitudes and perceptions about transferring to adult care}

The results of this current study revealed that adolescent and young adult LTRs perceive the importance of the transition process, but were not aware of the steps involved in preparing to transfer care to a new clinic. Less than half of the recipients and parents reported that they have given thought to transferring care, and just over half of those surveyed reported interest in learning about the transition process. As we hypothesized, older adolescent/young adults reported a greater level of interest and knowledge about transferring care to the adult clinic. This may relate to younger adolescents' difficulty envisioning a future which includes adult-centered services. Delays in abstract thinking observed in adolescence (20) may influence perspectives about the transition process. Indeed, for parents, recipient age was not related to the degree to which they thought about transition and transfer. Likewise, the level of interest or knowledge among the parents did not vary based on the recipient's age, or time since transplantation. It is noted, however, that patients older than 18 yr of age did not have corresponding parental reports. To address this limitation we are focusing efforts on assessing aspects of transition readiness among parents of our older adolescents/ young adults.

Adolescent/young adult LTRs and parents in the current investigation reported some degree of concern and worry about the transfer to adult clinic, with concerns about meeting new providers and leaving pediatric providers behind being the most commonly cited concerns. These reports are similar to previous assessments of patient and parent views of transition. For example, among children with special health care needs, barriers and resistance were most commonly related to perceptions of inferior care within the adult-oriented clinics as well as differences between pediatric and adult-centered care, and insurance coverage (21). In the absence of comparison groups or normative data on measures of transition readiness, we cannot conclusively determine what degree of knowledge or worry about transition is appropriate or expected.

Though patients and parents often report concerns and resistance to transferring care, little is known about how this impacts their adjustment to care once they present in the adult center. Boyle et al. examined patient and parent views of transition from pediatric to adult cystic fibrosis care prior to the transfer of care and again following the transfer of care (22). Prior to leaving pediatrics, patients and parents were concerned about risk of infection, leaving previous physicians, meeting a new care team, and a potential decrease in quality of medical care. Parents were most concerned about their child's ability to care for their health independently. Interestingly, post-transfer of care, there was a significant decrease in all areas of concern, except the risk for infection. The pediatric patients who met the adult team prior to transferring care had significantly less concern across all areas (22). Thus, perceptions of the transition process might be quite different if assessed following the transfer to adult-centered transplant care.

The patients and parents surveyed in this study expressed interest in learning more about the transition process, particularly with respect to the logistics of the transfer to the adult clinic. These comments were made in spite of ongoing, dedicated transition efforts in our clinic (11). Adolescent/young adults reported that they would prefer to receive information from either the pediatric or adult health care team, or via the internet/website. In contrast, the majority of parents stated that they would prefer to receive information directly from the pediatric health care providers. This underscores the importance of collaborating with the adolescent/young adult recipient and parent to determine how to best provide them with information related to the transition process. The fact that parents overwhelmingly wish to have information from the pediatric team may reflect their own attachment to the pediatric care providers. The relationship between the parent and the pediatric team is an important one to consider in transition planning (23-26). Overall, the prospective assessment of predictors of successful transition and transfer to adult-care is warranted to develop and implement effective transition programs. 
Responsibility for health self-management

The transition literature focuses on increasing adolescent readiness and independent health selfmanagement skills $(6,11,18,19)$. Our results indicate that responsibility for health management tasks is shared between adolescents and parents. In general, adolescent/young adult recipients are primarily responsible for remembering to take medications, while parents have primarily responsibility for tasks such as scheduling appointments, calling the office with questions and filling prescriptions. Yet, there was discordance between perceptions of responsibility between parents and adolescent/young adult recipients, suggesting that both the recipient and the parent perceive that they are individually more responsible than the other for the healthrelated task. Adolescents over allocated responsibility for health-related tasks to themselves, suggesting that adolescents perceive they have more responsibility for these tasks than what the parents perceive. The impact of perceptions of responsibility on self-management, including medication adherence, and health outcomes remains an empiric question worthy of further investigation.

As expected, compared to younger adolescents, the older teens and young adults endorsed more independence with healthcare tasks. Indeed, the promotion of independence with health management tasks is an integral component to transition planning. However, encouraging adolescent/ young adult recipients to have more independence with their medication regimen may have unintended, negative consequences. Lack of parental monitoring is associated with increased non-adherence among LTRs (11), adolescents diagnosed with type 1 diabetes (27) and HIV (16). Yet, parental over-involvement in health-related tasks has been cited as a barrier in the successful transition and transfer to adult-centered care (28). This presents a potential challenge in clinical care. Therefore, in addition to fostering independence and self-management in adolescents, attention must also be given to helping the parents gradually move from being the primary manager of health-related tasks toward being a supportive supervisor and consultant to their adolescent/ young adult $(11,29,30)$. This gradual shift should be based on the adolescent's acquisition of selfmanagement skills, rather than one based on chronological age alone.

\section{Limitations}

The current study sought to examine the attitudes and perceptions regarding the transition process among adolescent/young adult LTRs within a single center. To reduce response bias, we collected this information anonymously. Thus, we were unable to link responses with variables measuring medical stability or adherence. It is possible that medical issues, including history of rejection, re-transplantation, and/or medication non-adherence, may also impact perceptions and expectations about transferring to adult-centered care. To further examine the influence of these variables, we are collaborating with our adult liver transplant colleagues to examine the associations between transition readiness skills and perceptions, medical stability, adherence, and health status to refine our transition programming (11).

Another limitation of the current study relates to the lack of parental reports for the majority of respondents over the age of $18 \mathrm{yr}$, as most of these patients present independently in our clinic, precluding us from obtaining corresponding parental reports. This limits the generalizations we can make about the allocation of responsibility for health-related tasks among these young adults. This also limits the conclusions we can draw about the associations between recipient age and parent perceptions and attitudes about the transition process. In our continued quality improvement efforts, we are specifically targeting parents of adolescents/young adults between the ages of 18-25 yr to assist with program development.

This study was conducted in a single pediatric liver transplant center, which limited the sample size and the ability to generalize these findings to other pediatric transplant centers. For example, our program generally transfers pediatric patients to the adult transplant program within our University health system. This may influence perspectives about the transition process for our recipients and their parents. Specifically, because patients transfer care within the health system, they may not perceive that they are "leaving" as the facility is familiar, and the pediatric providers remain accessible. Likewise, patients may be reassured that there does not need to be a transfer of medical information as their new providers will have access to their complete electronic medical records. Additional studies of transition readiness and expectations among recipients and parents across pediatric transplant centers are warranted to develop consistent, and systematic interventions.

Lastly, this survey was not a comprehensive assessment of transition readiness or perspectives regarding transition to adulthood or adult-centered medical care. For example, aside from 
knowledge of reproductive health, we did not include an assessment of knowledge of general adolescent health issues. Indeed, many aspects of transition preparation can be encompassed by developmentally appropriate health care (5). Unfortunately, many adolescents and young adults do not receive recommended preventive counseling and screening on core topics including alcohol, tobacco, and substance use, sexual activity, depression, physical activity, and diet (31). Among pediatric transplant recipients, primary care concerns may be overlooked given the attention to transplant-specific issues, and transplant physicians may not have expertise in areas key to promoting overall health in adolescents and young adults (32). Yet, further work is needed to determine components of transition readiness, including general health promotion, that lead to optimal long-term health outcomes.

\section{Clinical implications and practice}

Despite methodological limitations, the present study has important clinical implications. There remains a need for empirically-driven transition programs in pediatric transplantation $(6,33)$. Transition programs in other pediatric populations, such as rheumatology (34) and cystic fibrosis (35) can serve as examples for pediatric solid organ transplant clinics. Yet, to date, there are few published reports describing transition programs in pediatric transplantation $(36,37)$. Information obtained through this study is presently being used to develop a transitional care program within our pediatric liver transplant clinic.

The existing transition literature recommends that transplant clinics have a designated healthcare transition coordinator to facilitate the transition process $(6,38,39)$. The transition coordinator role may be fulfilled by nurse practitioners, CCTN, and CCTC, pediatric psychologists and/or social workers $(36,38,39)$. A designated transition coordinator can assist with patient and family education, communication, and working toward meeting transitionrelated goals and milestones. Transition coordinators can also assist with preparing parents by educating them on strategies to increase the adolescent/young adult recipient's responsibility for healthcare tasks in a developmentally appropriate manner.

Our program has attempted to integrate recommendations from the literature as well as preliminary research from our center to develop a standard for transitional care. Within our pediatric liver transplant clinic, the transition process is facilitated primarily by the CCTN (VS) and pediatric psychologist (EMF). The CCTN serves as the primary transitional care coordinator and takes the lead in planning for the transfer of care by facilitating communication with the adult care providers, assisting with the development of medical summaries, and providing support and education to patients and their parents. The pediatric psychologist's efforts are primarily directed at the transition of health-care responsibility from parent to patient, and the acquisition of self-management skills. We take a team approach to transitional care, which involves consultation with the transplant clinic hepatologist, surgeons, dietician, nurses, and social workers in developing individual transition plans. For example, the physicians determine appropriateness of transfer by considering medical stability of the patient while the transplant team social worker facilitates issues related to logistics of transferring care, including transportation needs, and insurance coverage.

Based on results from this and previous work (11), as well as recommendations from the literature (6), we have incorporated standard assessment of transition readiness skills and allocation of responsibility for health-related tasks for all patients $11 \mathrm{yr}$ and older, and their parent/guardian. Assessment results are used to tailor intervention to the individual patient and family. Most often, clinic-based interventions target shifting responsibility for health-related tasks from parents to adolescents, appropriate parental monitoring and supervision, medication adherence, regimen knowledge, symptom recognition, and communication with healthcare providers. Given the high levels of concern among parents with respect to the transition process, we include adolescents/young adults and their parents, when present, in setting self-management and transition-related goals. This typically involves assisting parents in delegating responsibility for health-related tasks to their adolescent in a gradual and developmentally appropriate manner.

Additional aspects of our transition program development goals include developing mentoring programs to allow adolescents/young adults and their parents to connect with individuals who have successfully transferred from pediatric to adult-centered care (9), as well as "meet the team" events to allow an opportunity for patients and parents to meet and interact with the adult care team prior to the transfer of care.

\section{Conclusions}

In summary, transition is a continuous process and should incorporate routine assessment and 
interventions to promote self-management skills as pediatric patients prepare to move from childcentered care to adult-centered care. Adolescent/ young adults and parents perceive the importance of transition planning, and reported interest in learning about the transition process. Deficits appear to be related to knowledge about the logistics related to the transfer of care, as well as perceived independence with self-management skills. Transition programs should have designated team members to lead efforts in coordinating the transition process in order to provide timely education, communication, and collaboration among patients, families, pediatric transplant teams, and adult transplant teams. Researchers and clinicians should continue to focus on identifying predictors of successful health care transitions to develop and implement transition programs to ensure that adolescents, young adults, and their parents are receiving the necessary resources and support necessary for independent self-management and the transfer to adult-centered care.

\section{Acknowledgments}

This work was supported by funds from Grant Number \# UL1RR024986 from NCRR CTSA funding to Emily M. Fredericks, PhD.

\section{References}

1. Magee J. Scope of the Problem: Registry Data. Presented at the Transition to Adult Care for Adolescent Transplant Recipients: A jointly sponsored consensus conference. Chicago, IL, 2005.

2. MageE J. Growing up is hard to do: Transitional care from pediatrics to adulthood. In: 6th Annual ASTS Winter Symposium. Scottsdale, Arizona, 2006.

3. Blum RW, Garell D, Hodgman CH, et al. Transition from child-centered to adult health-care systems for adolescents with chronic conditions. A position paper of the Society for Adolescent Medicine. J Adolesc Health 1993: 14: 570-576.

4. Sawyer SM, Blair S, Bowes G. Chronic illness in adolescents: Transfer or transition to adult services? J Paediatr Child Health 1997: 33: 88-90.

5. Kennedy A, SAwyer S. Transition from pediatric to adult services: Are we getting it right? Curr Opin Pediatr 2008: 20: 403-409.

6. Bell Le, Bartosh SM, Davis CL, et al. Adolescent transition to adult care in solid organ transplantation: A consensus conference report. Am J Transplant 2008: 8: 2230-2242.

7. Kennedy A, Sloman F, Douglass JA, Sawyer SM. Young people with chronic illness: The approach to transition. Intern Med J 2007: 37: 555-560.

8. Dommergues JP, Letierce A, Gravereau L, Plainguet F, Bernard O, Debray D. Current lifestyle of young adults after liver transplantation during childhood. Am J Transplant 2010: 10: $1634-1642$.

9. McCurdy C, DiCenso A, Boblin S, Ludwin D, BryantLukosius D, Bosompra K. There to here: Young adult patients' perceptions of the process of transition from pediatric to adult transplant care. Prog Transplant 2006: 16: 309-316.
10. McDonagh JE, Kaufman M. Transition from pediatric to adult care after solid organ transplantation. Curr Opin Organ Transplant 2009: 14: 526-532.

11. Fredericks EM, Dore-Stites D, Well A, et al. Assessment of transition readiness skills and adherence in pediatric liver transplant recipients. Pediatr Transplant 2010: 14: 944-953.

12. Annunziato RA, Parkar S, Dugan CA, et al. Brief report: Deficits in health care management skills among adolescent and young adult liver transplant recipients transitioning to adult care settings. J Pediatr Psychol 2011: 36: 155-159.

13. Willoughiy LM, Fukami S, Bunnapradist S, et al. Health insurance considerations for adolescent transplant recipients as they transition to adulthood. Pediatr Transplant 2007: 11: 127131.

14. Annunziato RA, Emre S, Shneider B, Barton C, Dugan CA, Shemesh E. Adherence and medical outcomes in pediatric liver transplant recipients who transition to adult services. Pediatr Transplant 2007: 11: 608-614.

15. McPherson M, Thaniel L, Minniti CP. Transition of patients with sickle cell disease from pediatric to adult care: Assessing patient readiness. Pediatr Blood Cancer 2009: 52: 838-841.

16. NaAR-King S, Montepiedra G, Nichols S, et al. Allocation of family responsibility for illness management in pediatric HIV. J Pediatr Psychol 2009: 34: 187-194.

17. Walders N, Drotar D, Kercsmar C. The allocation of family responsibility for asthma management tasks in AfricanAmerican adolescents. J Asthma 2000: 37: 89-99.

18. Weissberg-Benchell J, Wolpert H, Anderson BJ. Transitioning from pediatric to adult care: A new approach to the post-adolescent young person with type 1 diabetes. Diabetes Care 2007: 30: 2441-2446.

19. McDonagh Je, Southwood TR, Shaw KL. The impact of a coordinated transitional care programme on adolescents with juvenile idiopathic arthritis. Rheumatology 2007: 46: 161-168.

20. Casey BJ, Getz S, Galvan A. The adolescent brain. Dev Rev 2008: 28: 62-77.

21. Reiss JG, Gibson RW, WALKer LR. Health care transition: Youth, family, and provider perspectives. Pediatrics 2005: 115: $112-120$.

22. Boyle MP, Farukhi Z, Nosky ML. Strategies for improving transition to adult cystic fibrosis care, based on patient and parent views. Pediatr Pulmonol 2001: 32: 428-436.

23. Moons P, Pinxten S, Dedroog D, et al. Expectations and experiences of adolescents with congenital heart disease on being transferred from pediatric cardiology to an adult congenital heart disease program. J Adolesc Health 2009: 44: 316-322.

24. Anthony SJ, Kaufman M, Drabble A, Seifert-Hansen M, Dipchand AI, Martin K. Perceptions of transitional care needs and experiences in pediatric heart transplant recipients. Am J Transplant 2009: 9: 614-619.

25. LANDAU LI. Cystic fibrosis: Transition from paediatric to adult physician's care. Thorax 1995: 50: 1031-1032.

26. Rosen D. Between two worlds: Bridging the cultures of child health and adult medicine. J Adolesc Health 1995: 17: 10-16.

27. Horton D, Berg CA, Butner J, Wiebe DJ. The role of parental monitoring in metabolic control: Effect on adherence and externalizing behaviors during adolescence. J Pediatr Psychol 2009: 34: 1008-1018

28. Clarizia na, Chahal N, Manlhiot C, Kilburn J, Redington AN, McCrindle BW. Transition to adult health care for adolescents and young adults with congenital heart disease: Perspectives of the patient, parent and health care provider. Can J Cardiol 2009: 25: e317-e322.

29. Kieckhefer GM, Trahms CM. Supporting development of children with chronic conditions: From compliance toward shared management. Pediatr Nurs 2000: 26: 354-363. 


\section{Fredericks et al.}

30. Gall C, Kingsnorth S, Healy H. Growing up ready: A shared management approach. Phys Occup Ther Pediatr 2006: 26: 47-62.

31. American Academic of Pediatrics CoA. Achieving quality health services for adolescents. Pediatrics 2008: 121: 1263-1270.

32. Bucuvalas J, Alonso E, Magee J, Talmalkar J, Hanto D, Doo E. Improving long-term outcomes after liver transplantation in children. Am J Transplant 2008: 8: 1-8.

33. McDonagh JE, Kelly DA. The challenges and opportunities for transitional care research. Pediatr Transplant 2010: 14: 688-700.

34. McDonagh JE. Young people first, juvenile idiopathic arthritis second: Transitional care in rheumatology. Arthritis Rheum 2008: 59: 1162-1170.

35. McLaughlin Se, Diener-West M, Indurkhya A, Rubin H, Heckmann R, Boyle MP. Improving transition from pediatric to adult cystic fibrosis care: Lessons from a national survey of current practices. Pediatrics 2008: 121: e1160-e1166.

36. Annunziato RA, Hogan B, Barton C, et al. A translational and systemic approach to transferring liver transplant recipients from pediatric to adult-oriented care settings. Pediatr Transplant 2010: 14: 823-829.

37. Annunziato RA, Emre S, Shneider BL, et al. Transitioning health care responsibility from caregivers to patient: A pilot study aiming to facilitate medication adherence during this process. Pediatr Transplant 2008: 12: 309-315.

38. Fredericks EM. Nonadherence and the transition to adulthood. Liver Transpl 2009: 15(Suppl 2): S63-S69.

39. Betz CL, Redcay G. Dimensions of the transition service coordinator role. J Spec Pediatr Nurs 2005: 10: 49-59. 